\title{
Readmission rates: Haven't I seen you somewhere before?
}

\author{
Alan M. Speir, MD \\ From the Department of Cardiac Surgery, Inova Heart and Vascular Institute, Falls Church, Va. \\ Disclosures: Medtronic North American Cardiac Surgery Advisory Board. \\ Received for publication Nov 27, 2017; accepted for publication Dec 2, 2017. \\ Address for reprints: Alan M. Speir, MD, Department of Cardiac Surgery, Inova Heart and Vascular Institute, 3300 \\ Gallows Rd, Falls Church, VA 22042 (E-mail: aspeir1@gmail.com). \\ J Thorac Cardiovasc Surg 2018;155:2048-9 \\ $0022-5223 / \$ 36.00$ \\ Copyright (c) 2017 by The American Association for Thoracic Surgery \\ https://doi.org/10.1016/j.jtcvs.2017.12.016
}

Hospital readmission rates are a commonly reviewed quality metric in most hospitals today. There remains, however, significant discrepancy in the reporting of such rates, particularly in postoperative cardiac surgery patients, with relevant differences noted between what is reported to the Society of Thoracic Surgeons (STS) National Adult Cardiac Surgery Database and what is reported to the individual institutions from the Centers for Medicare \& Medicaid Services. In this issue of the Journal, this discrepancy and the opportunities and challenges to resolve such differences are well described by Edgerton and colleagues ${ }^{1}$ in their article "Can Use of an Administrative Database Improve Accuracy of Hospital Reported Readmission Rates?',

Their manuscript reviews the analysis of 45,539 STS records from January 2008 to December 2016 from 28 hospitals performing cardiac surgery (from 5 different hospital systems) collected in their regional quality consortium (Texas Quality Initiative) compared with shared administrative claims data from 81 area hospitals. The authors noted that the reported STS readmission rate of $10.5 \%$ underreported the readmission rate by 2.5 actual percentage points, stating "The true rate should have been $13.0 \%$. Actual readmission rate was $23.8 \%$ higher than reported by the clinical database. Approximately $36 \%$ of readmissions were to a hospital that was a part of a different hospital system.",

This challenge to accurately collect and evaluate readmission rates in postoperative cardiac surgery patients is certainly not a new issue and has been the focus of numerous studies that have sought to define risk factors for hospital readmission after cardiac operations. ${ }^{2-6}$ Shahian and colleagues ${ }^{7}$ evaluated the readmission rates after isolated coronary artery bypass grafting between 2008 and 2010 and demonstrated the rate obtained from the STS database was $10 \%$ compared with $16.8 \%$ obtained from the Medicare data. Moreover, not only is the accurate measurement of such rates often in question, but the relevance of readmission as a measure of hospital quality continues to remain controversial and confusing. Shih and Dimick ${ }^{8}$ clearly documented that "readmission rates are pital quality." population.

\section{References} 2003;290:773-80.

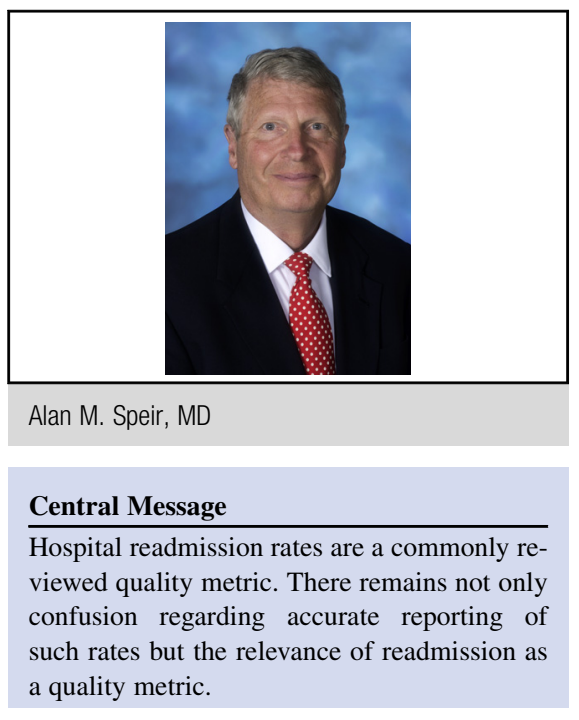

See Article page 2043.

not a reliable measure of hospital quality in cardiac surgery" and "the proposed financial penalties will largely be determined by chance and not by true differences in hos-

Although it is enticing for cardiac and thoracic surgeons to discount the importance of readmission rates based on these limitations, it is still incumbent on us to be a part of the solutions to improve postdischarge care coordination and limit readmission. Contacting the patients directly within 2 days postdischarge, patient office visits within 3 to 4 days from discharge, and active collaboration with the visiting nurses and/or staff in postacute care facilities with standardization of expectations and order sets are only several of the options available to reduce readmissions. Regardless of the cancellation of the Centers for Medicare \& Medicaid Services Episode Payment Model and Cardiac Rehabilitation Incentive program for bundled payment care incentive for isolated coronary artery bypass grafting, cardiothoracic surgeons may still lead such quality initiatives that will only benefit our patient outcomes and continue to reduce the costs of care delivery for this patient

1. Edgerton JR, Herbert MA, Hamman BL, Ring WS. Can use of an administrative database improve accuracy of hospital reported readmission rates. J Thorac Cardiovasc Surg. 2018;155:2043-7.

2. Hannan EL, Racz MJ, Walford G, Ryan TJ, Isom OW, Bennett E, et al. Predictors of readmission for complications of coronary artery bypass graft surgery. JAMA. 
3. Hannan EL, Zhong Y, Lahey SJ, Culliford AT, Gold JP, Smith CR, et al. 30-day readmissions after coronary artery bypass graft surgery in New York State. JACC Cardiovasc Interv. 2011;4:569-76.

4. Slamowicz R, Erbas B, Sundararajan V, Dharmage S. Predictors of readmission after elective coronary artery bypass graft surgery. Aust Health Rev. 2008;32:677-83.

5. Li Z, Armstrong EJ, Parker JP, Danielsen B, Romano PS. Hospital variation in readmission after coronary artery bypass surgery in California. Circ Cardiovasc Qual Outcomes. 2012;5:729-37.
6. Fox JP, Suter LG, Wang K, Wang Y, Krumholz HM, Ross JS. Hospital-based, acute care use among patients within 30 days of discharge after coronary artery bypass surgery. Ann Thorac Surg. 2013;96:96-104.

7. Shahian DM, He X, O'Brien SM, Grover FL, Jacobs JP, Edwards FH, et al. Development of a clinical registry based 30-day readmission measure for coronary artery bypass grafting. Circulation. 2014;130:399-409.

8. Shih T, Dimick JB. Reliability of readmission rates as a hospital quality measure in cardiac surgery. Ann Thorac Surg. 2014;97:1214-9. 